\title{
Demand and Practice of Digital Fashion Market During COVID-19
}

\author{
Fiona Paulson. T \\ Nehru Arts and Science College, Coimbatore, Tamil Nadu, India
}

\begin{abstract}
The search for skills and competences in the digital fashion job market represents a very important issue due to the fast development of the dynamic nature of the fashion field. Companies in the field need to continuously adapt in order to stay in the competitive world. This requires a continuous update of skills. This research will help to acknowledge and evaluate the current situation concerning market practices and needs in the digital fashion domain
\end{abstract}

Keywords: skill, fashion field, dynamic nature

\section{Introduction}

The fashion industry has been impacted by ICTs (Sousa et al.2019) and it is trying to adapt to the digital world by remodelling business processes and systems. These technological advancements are challenging existing ways of conducting business on different levels:

- They are employed in the production cycle

- They affect marketing, distribution and sales

- They are extensively used in communication activities (Kalbaska and Cantoni, 2019).

The global pandemic Covid - 19 is spreading human suffering, disrupting people's lives and damaging the global economy. The fashion industry global annual revenues before the pandemic, has been highly impacted with unemployment and financial hardship. According to the "Coronavirus Update to The State of Fashion 2020" by Business of Fashion et al. (2020), the estimated revenues for the global fashion industry will contract, for apparel and footwear sector, by $30 \%$ and for the personal luxury good industry by $39 \%$ in 2020 . The damaging impact of the pandemic, fashion companies have been forced to develop the digital adaptation process, transform age - old industry practices. Virtual fashion shows, digital show rooms, livestream commerce and 3D design tools are just a few of the technological advancements that companies have been trying to implement in order to overcome the global emergency. According to "The State of Skills in the Apparel Industry" by Alvanon et al. (2018) two main issues arise from searching employees with the appropriate digital fashion skills. While a growing awareness the digital fashion skill gap, few studies have focused on the competences and skills needed in the current fashion job market.

This research aims to assess digital fashion market practices and needs during Covid19 emergency. In particular

- What are the specific job roles within digital fashion domain in the current marketplace, which is undergoing a critical transformation due to Covid19?

- What are the skills and competences needed today in the digital fashion domain?

\section{Methodology}

Digital fashion related job postings were analysed through LinkedIn, a business and employment oriented social networking service (SNS). LinkedIn is the most popular web design with 675 million users around the world, of which 211 million in India. It operates in 24 different languages and gathers 30 million companies around the world (Cooper, 2020).3D, Augmented Reality, CRM, Digital Communication, Digital Content, Digital Fashion, Digital Marketing, Digital Media, Digital Transformation, eCommerce, eLearning, Fashion IT, Forecasting, Influencer Marketing, Localisation, Personalisation, SEO/SEM, Social Media, Trade Marketing, Usability, User Experience, Visual Merchandising, Web Analytics. The following industries were taken into consideration: Apparel and Fashion, Internet, Luxury Goods and Jewellery, Marketing and Advertising, Retail, Textile and Design. Job postings published twice by the fashion brand itself and by an HR company were taken into consideration only once. The analysis of digital fashion related job postings on LinkedIn conducted in 28 States of Indian and in Switzerland resulted in 1397 job postings. Quantitative content analysis of job titles and job descriptions was then performed using Word Smith Tool 6.

\section{Result}

The results are presented in the subsequent sections: (a) number of available job positions in every country, (b) analysis of available job titles in the digital fashion domain and (c) analysis of the digital fashion skills extracted from the job descriptions. a. Available jobs in the digital fashion domain The research of open digital fashion job positions on LinkedIn produced results in $25 \mathrm{EU}$ countries and Switzerland. No job positions were found in the Republic of Cyprus, Latvia and Malta.

a) Digital fashion positions were advertised on LinkedIn during the period of the data collection (from 19.05.2020 to 02.06 .2020 ) with the related number of available job positions. 
Table 1: Number and percentual of digital fashion jobs

\begin{tabular}{|l|c|c|}
\hline Countries & Frequencies & $\%$ \\
\hline Austria & 11 & 0.8 \\
\hline Belgium 34 2 & 34 & 2 \\
\hline India & 12 & 0.9 \\
\hline Romania & 50 & 4 \\
\hline UK & 629 & 45 \\
\hline Sweden & 23 & 4 \\
\hline Germany & 203 & 14 \\
\hline
\end{tabular}

These results should be carefully evaluated due to the fact that the analysis was undertaken on the dataset in English. This might have had an impact on the number of available job. The hubs of the digital fashion domain today in Europe are the United Kingdom (629) and Germany (203) present a consistent number of job offerings in English.

\section{b) Digital fashion related job titles}

Quantitative content analysis was performed in order to understand and evaluate specific job titles that are on request in the current job market within the digital fashion domain.

\begin{tabular}{|l|l|}
\hline Keyword Combination & $\#$ \\
\hline eCommerce & 55 \\
\hline Digital marketing & 49 \\
\hline Visual associate & 44 \\
\hline Product manager & 41 \\
\hline Social media & 41 \\
\hline Marketing manager & 39 \\
\hline Sales associate & 38 \\
\hline Sales consultant & 35 \\
\hline Store manager & 31 \\
\hline Customer service & 30 \\
\hline Fashion assistant & 27 \\
\hline Manager digital & 25 \\
\hline Account manager & 23 \\
\hline
\end{tabular}

Table 2 presents a list of the most frequent combinations of keywords found in digital fashion job titles. Keywords combinations

The results show the most frequent combinations of words in job titles. eCommerce (55), digital marketing (49) and social media (41) are the three most desired areas of jobs, while visual associate (44), product manager (41), marketing manager (39), sales associate (38), sale consultant (35) and store manager (31) are the most desired job professions.

\section{Conclusion}

The search for skills and competences in the digital fashion job market represents a very important issue due to the fast development of the dynamic nature of the fashion field. Companies in the field need to continuously adapt in order to stay in the competitive world. This requires a continuous update of skills. This research will help to acknowledge and evaluate the current situation concerning market practices and needs in the digital fashion domain and it will have a practical impact for professionals in the recruitment departments as well as professionals in charge of workforce training activities within fashion brands. This research utilized a single platform, LinkedIn social networking service, hence the results of this sample of analysis should be carefully generalized and it is focused on job postings published in English. 